\title{
A New Governance Model for the CSHP: Setting a Course for the Future
}

\author{
Janice Munroe
}

Ts The world has changed substantially since the Canadian Society of Hospital Pharmacists (CSHP) was founded 64 years ago. For example, when people needed directions to a destination, that guidance came in the form of a map, with or without a compass. Now, in the 21st century, we more commonly use a Global Positioning System (GPS) unit. In the case of the CSHP, our GPS is a "Governance Policy and Standard".

You may have heard that the CSHP Bylaws Committee recently completed a comprehensive review and revision of the Society's bylaws. The new draft bylaws required some additional modification to ensure alignment with the recently enacted Canada Not-for-profit Corporations Act before undergoing review by legal counsel. At that point, it became apparent that our GPS was "off target", as our current governance modelour way of doing business - potentially places both our member volunteers and the Society at risk with respect to financial and legal liabilities. Fortunately, CSHP has not encountered any major challenges with the current model. But the potential for problems exists, and CSHP would not be acting responsibly if it continued without updating the governance model.

To ensure that both CSHP volunteers and the Society as a whole are protected appropriately, we must adopt a recognized governance model that has proven fiscally and legally sound. During meetings held in conjunction with the Summer Educational Sessions this past August, CSHP Council carefully reviewed several established governance models. Council chose a model of governance that will allow CSHP branches to retain as much autonomy as possible, while establishing clear and transparent lines of reporting and accountability.

From a member's perspective, there will be no changes in the communications you receive, the delivery of educational programs, or payments for membership.

However, the branches will see more substantial changes, especially in terms of how their finances are handled. Currently, branches receive and disperse revenue through individual branch bank accounts. Under the new governance model, closer financial integration will be established between the branches and the National Office. This means that branch members who sign legal contracts when planning educational events "on behalf of CSHP" will no longer be potentially liable.

Over the years, CSHP has thrived because of the involvement, commitment, and generous contributions of its members. We must take steps to ensure that CSHP members and the Society are operating responsibly within the parameters of Canadian law and according to generally accepted accounting principles. The new governance model will provide important protection from personal legal and financial liability for CSHP members and for the Society as a whole.

Branch delegates will now bring the details of and the rationale for adopting the proposed model to their respective branches. The draft bylaws will be revised to reflect the new governance model, followed by approval of the bylaws by Council in March 2012 and a membership vote to adopt the bylaws at the August 2012 CSHP Annual General Meeting in Charlottetown, Prince Edward Island, site of the Canadian Confederation Conference back in September 1864.

It is very important that the CSHP "GPS" be on target, sending us safely in the right direction as we head into the future!

Janice Munroe, BScPharm, is President and Internal Liaison of the Canadian Society of Hospital Pharmacists. 